\title{
LEGISLAÇÁO AMBIENTAL PARA AS COMUNIDADES QUILOMBOLAS
}

\author{
ENVIRONMENTAL LEGISLATION FOR QUILOMBOLES COMMUNITIES
}

\author{
Rosele Clairete dos Santos ${ }^{\mathrm{I}}$ \\ Mariane Roman Menegon ${ }^{\mathrm{II}}$
}

I Universidade Estadual do Rio Grande do Sul, Soledade, RS, Brasil. Doutora em Ciências do Solo. E-mail: rosele-santos@ uergs.edu.br

II Associação Sulina de Crédito e Assistência Rural, Restinga Seca, RS, Brasil. Especialista em Práticas Educacionais em Ciências e Pluralidade. E-mail: marianermenegon@gmail.com

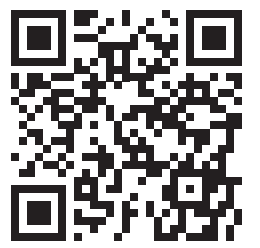

DOI: http://dx.doi.org/10.20912/rdc.v15i37.211

Recebido em: 08.01.2020

Aceito em: 21.07.2020
Resumo: Introdução: As comunidades rurais são mais sujeitas a processos de empobrecimento, sendo visível que a vulnerabilidade social causa maior preocupação no meio rural do que no urbano. Neste contexto, os Povos e Comunidades Tradicionais apresentam necessidades de desenvolvimento de políticas públicas que envolvam os seus territórios. Objetivo: analisar a legislação que institui as políticas públicas, em âmbito nacional, direcionada para povos e comunidades tradicionais, em especial as comunidades quilombolas. Metodologia: Trata-se de uma pesquisa documental, que buscou na web, as normas legais que tratam da questáo ambiental no Brasil. Resultados: Foram encontrados 35 atos normativos, entre os anos de 1964 e 2019, sendo selecionados apenas os vigentes, compondo a lista de documentos: uma constituição, quinze decretos, três instruções normativas, quatorze leis federais e duas resoluções. Estas legislaçóes foram discutidas no contexto dos Povos e Comunidades Tradicionais. Conclusão: Por fim, nota-se que as legislaçóes ambientais que instituem as políticas públicas contemplam estes povos, por serem grupos que apresentam em seus traços culturais a conservação da biodiversidade, o uso sustentável dos recursos naturais e o equilíbrio ecológico. Entretanto não significa que estas regulamentaçóes estejam implementadas e contribuindo para a proteçáo destas comunidades.

Palavras-chave: Povos e Comunidades Tradicionais. Políticas Públicas. Legislação Ambiental.

Abstract: Introduction: Rural communities are more subject to impoverishment processes, and social vulnerability is more severe in rural than in urban areas. In this context, the Traditional Peoples and Communities present needs for the development of public policies that involve their territories. Objective: To analyze the legislation that institutes public policies, at national level, aimed at traditional peoples and communities, especially quilombola communities. Methodology: This is a documentary research, which searched the web, the legal norms that deal with the environmental issue in Brazil Results: A total of 35 normative acts were found between 1964 and 2019, and only those in force were 
selected, composing the list of documents: one constitution, fifteen decrees, three normative instructions, fourteen federal laws and two resolutions. These legislations were discussed in the context of Traditional Peoples and Communities. Conclusion: Finally, it is noted that the environmental laws that institute public policies cover these peoples, as they are groups that present in their cultural traits the conservation of biodiversity, the sustainable use of natural resources and ecological balance. However, it does not mean that these regulations are implemented and contributing to the protection of these communities.

Keywords: Traditional Peoples and Communities. Public Policies. Environmental Legislation.

\section{Introdução}

Povos e comunidades tradicionais são grupos diferenciados culturalmente e que se reconhecem entre si, com formas próprias de organização social, que ocupam seu território e recursos naturais. Com isso, desenvolvem sua cultura ancestral, social e religiosa, utilizando conhecimentos e práticas transmitidos pela tradição ${ }^{1}$. A diversidade do povo brasileiro que vive no meio rural é reconhecida pela Lei Federal No 11.326, de 24 de julho de 2006, que "Estabelece as diretrizes para a formulação da Política Nacional da Agricultura Familiar e Empreendimentos Familiares Rurais", a qual reconhece extrativistas, indígenas, quilombolas, pescadores e demais povos e comunidades tradicionais (PCTs) como públicos beneficiários das políticas de agricultura familiar ${ }^{2}$.

As comunidades quilombolas foram historicamente consideradas ilegais no Brasil, permanecendo as margens das políticas públicas. Atualmente estes povos ainda sofrem com a significativa vulnerabilidade social ${ }^{3}$. A Constituição da República Federativa do Brasil (CRFB), de 05 de outubro de 1988, em seu artigo 68, do Ato das Disposiçóes Constitucionais Transitórias (ADCT), assegura os direitos de titulação de terras para os povos quilombolas que estejam ocupando suas áreas, sendo concedido e reconhecido a propriedade definitiva, através da emissão da titularidade da terra. Entretanto, somente duas décadas após a publicação deste artigo, o mesmo foi regulamentado, por meio do Decreto Federal No 4.887, de 20 de novembro de 2003, que "Regulamenta o

1 BRASIL. Decreto Federal No 6.040, de 07 de fevereiro de 2007. Institui a Política Nacional de Desenvolvimento Sustentável dos Povos e Comunidades Tradicionais. Publicação: Diário Oficial da União - 08/02/2007, P 316 (Publicação Original). Disponível em: http://www.planalto.gov.br/ccivil_03/_ato2007-2010/2007/decreto/ d6040.htm. Acesso em: 20 jun. 2019

2 MENDONÇA, Leticia Koeppel; TAVIRA, Guilherme; FERREIRA, Everton; LANGE, Roberta; OLIVEIRA, Luana Paré; MOLINA, Caroline; HORA, Karla. A construção de uma política de assistência técnica e extensão rural para superação da extrema pobreza. In: MELLO, Janine. A inclusão produtiva rural no Brasil Sem Miséria: o desafio da superação da pobreza no campo. Brasília: MDS. p. 50-69. 2015.

3 MENDONÇA, Leticia Koeppel; TAVIRA, Guilherme; FERREIRA, Everton; LANGE, Roberta; OLIVEIRA, Luana Paré; MOLINA, Caroline; HORA, Karla. A construção de uma política de assistência técnica e extensão rural para superação da extrema pobreza. In: MELLO, Janine. A inclusão produtiva rural no Brasil Sem Miséria: o desafio da superaçáo da pobreza no campo. Brasília: MDS. p. 50-69. 2015. 
procedimento para identificação, reconhecimento, delimitação, demarcação e titulação das terras ocupadas por remanescentes das comunidades dos quilombos de que trata o art. 68 do Ato das Disposiçóes Constitucionais Transitórias”, e em 2007 através do Decreto Federal No 6.040, de 07 de fevereiro de 2007, que "Institui a Política Nacional de Desenvolvimento Sustentável dos Povos e Comunidades Tradicionais", os quilombolas foram reconhecidos como Povos e Comunidades Tradicionais ${ }^{4}$.

As formulações de normas legais específicas são políticas afirmativas que garantem a visibilidade dos povos e comunidades tradicionais. Porém, não significa que os problemas estejam todos resolvidos e os direitos assegurados. Assim, há uma imensa disputa social de interesses públicos e particulares, além de projetos divergentes que colocam em xeque a demarcação e titularidade de terras quilombolas e reservas indígenas, a identidade social e cultural desses grupos, levando a uma constante luta para garantir seus direitos ${ }^{5}$.

Este artigo tem como objetivo analisar a legislação que institui as políticas públicas, em âmbito nacional, direcionada para povos e comunidades tradicionais, em especial as comunidades quilombolas. A pesquisa documental pode ser definida como aquela capaz de produzir novos conhecimentos, através da criação de outras formas de compreender os fenômenos, de conhecer como se relacionam e como vem sendo estudados ${ }^{6}$. Por meio da pesquisa documental, os pesquisadores têm a capacidade de coletar, tratar e analisar as fontes de informaçóes ${ }^{7}$.

Foi realizada uma busca no site oficial do Ministério do Meio Ambiente, por meio da ferramenta de busca "Painel Legislação Ambiental", que disponibiliza 2.770 atos normativos em relaçáo à legislação ambiental brasileira. Foram utilizados como termos de busca "Povos e Comunidades Tradicionais"; "Comunidades Tradicionais"; "Quilombo"; e "Quilombolas". Havia a opção em selecionar o conteúdo específico, entretanto, apenas cinco atos normativos foram encontrados. Assim, foi realizada a pesquisa em todo o acervo de legislação ambiental. Foram encontrados 35 atos normativos, entre os anos de 1964 e 2019, sendo selecionados apenas os vigentes, a saber: uma constituição, quinze decretos, três instruçóes normativas, quatorze leis federais e duas resoluçóes. Além de analisar a Política Nacional de Assistência Técnica e Extensão Rural (PNATER).

4 BRASIL. Decreto Federal No 6.040, de 07 de fevereiro de 2007. Institui a Política Nacional de Desenvolvimento Sustentável dos Povos e Comunidades Tradicionais. Publicação: Diário Oficial da União - 08/02/2007, P 316 (Publicação Original). Disponível em: http://www.planalto.gov.br/ccivil_03/_ato2007-2010/2007/decreto/ d6040.htm. Acesso em: 20 jun. 2019

5 CALEGARE, Marcelo Gustavo Aguilar; HIGUCHI, Maria Inês Gasparetto; BRUNO, Ana Carla dos Santos. Povos e Comunidades Tradicionais: Das áreas protegidas à visibilidade política de grupos sociais portadores de identidade étnica e coletiva. Ambiente \& Sociedade, São Paulo, v. 17, n. 3, p. 115-134, 2014.

6 SÁ-SILVA, J. R; ALMEIDA, C. D; GUINDANI, J. F. Pesquisa documental: pistas teóricas e metodológicas. Revista Brasileira de História Ciências Sociais, v. 1, n. 1, p. 1-15, 2009.

7 GARCIA JUNIOR, E. F; MEDEIROS, S; AUGUSTA, C. Análise documental: uma metodologia da pesquisa para a Ciência da Informação. Temática, v. 13, n. 7, p. 138-150, 2017. 
Foram incluídos atos normativos, no período de 1964 à 2019, vigentes, que versavam sobre os povos e comunidades tradicionais, em especial sobre as comunidades quilombolas. Para realizar a análise da legislação ambiental procurou-se demonstrar os padróes de proximidade entre os elementos pesquisados, visando uma melhor compreensão das normas e sua possível aplicabilidade na realidade dos povos e comunidades tradicionais. Além de analisar o quanto a legislaçóes contribuem para o desenvolvimento sustentável destas comunidades.

Este estudo tem como questão de pesquisa: como as legislaçóes ambientais brasileiras que instituem as políticas públicas contemplam os povos e comunidades tradicionais, em especial as comunidades quilombolas?

\section{Contexto histórico dos povos e comunidades tradicionais: quilombolas}

Quilombo na origem histórica do Brasil Colonial significa resistência dos escravos frente ao regime escravocrata imposto na época, embora na essência africana, quilombo, signifique povoação. Os escravos fugitivos formavam as "comunidades ilegais", com organização própria, produção diversificada e uso sustentável da terra, desta forma tornando-se um perigo ao sistema latifundiário e monocultor vigente ${ }^{8}$.

Segundo a Fundação Cultural Palmares (FCP), as comunidades quilombolas tiveram origem a partir dos quilombos, pois estes eram locais que concentravam um grande número de negras e negros que se rebelaram contra o regime colonial. A partir da Constituição Federativa do Brasil de 1988, o termo quilombo foi ampliado, sendo considerada toda área ocupada pelas comunidades remanescentes dos quilombos antigos?.

A abolição da escravidão dos afrodescendentes deu-se a partir da assinatura da Princesa Isabel em 13 de maio de 1888 da Lei Áurea. Durante muitas décadas, os escravocratas continuaram se organizando politicamente, pois os escravos precisavam "comprar" a sua liberdade como forma de reparação aos senhores. Nesse sentido, havia uma demanda de indenizaçóes para conceder aos recém-libertos o direito à ocupação das terras. Mas somente um século depois que os remanescente de quilombos viram a possibilidade de concretizar o direito da titularidade das terras com a regulamentaçáo, conforme o artigo 68 do ADCT da Constituiçãa ${ }^{10}$.

$\mathrm{O}$ artigo supracitado pode ser considerado como um ato reparatório aos descendentes dos escravos africanos. Pois, estes, apesar da abolição da escravatura, não usufruíram dos direitos que lhes eram assegurados, pois permaneciam dependentes dos

8 MACEDO, Joāo Heitor Silva. Cultura, educação e ensino de história. Combate ao racismo: narrativas sobre a lei 10.639/03. 2018. 221f. Tese (Doutorado em História) - Centro de Ciências Sociais e Humanas, Departamento de História, Universidade Federal de Santa Maria, 2018.

9 MACEDO, João Heitor Silva. Cultura, educação e ensino de história. Combate ao racismo: narrativas sobre a lei 10.639/03. 2018. 221f. Tese (Doutorado em História) - Centro de Ciências Sociais e Humanas, Departamento de História, Universidade Federal de Santa Maria, 2018.

10 MATTOS, Hebe. "Remanescentes das comunidades dos quilombos": Memória do cativeiro e políticas de reparação no Brasil. Revista USP, São Paulo, n. 68, p. 104-111, 2005/2006. 
fazendeiros, para trabalhar a terra, plantar produtos para subsistência, como milho, feijão, mandioca e para se alimentar ${ }^{11}$. Mantinham uma relação de dependência dos seus senhores e assim, não tinham sua liberdade garantida simplesmente pela assinatura da lei.

\section{Relação das comunidades quilombolas com o meio ambiente}

Possuidores de uma relação diferenciada com a terra ${ }^{12}$, o termo "Povos e Comunidades Tradicionais” emergiu do movimento ambientalista na década de 1980. Estes grupos eram reconhecidos pela maneira diferenciada de se relacionar com o meio ambiente, trazendo características socioculturais que se traduzem em uma forma específica de pensar a produção, a economia e o território ${ }^{13}$.

A agropecuária assume papel importante na economia brasileira, mas também é responsável por importantes impactos ambientais negativos que precisam ser considerados no processo de formulaçáo das políticas de desenvolvimento rural. No mesmo sentido, existe um ritmo acelerado de crescimento populacional que, aliado ao padrão de vida da sociedade, tem afetado de forma negativa o meio ambiente somado as mudanças climáticas, a qualidade dos recursos hídricos, a biodiversidade e produção de alimentos, colocando em risco a sobrevivência das gerações futuras ${ }^{14}$.

As comunidades quilombolas desenvolvem relaçóes específicas com o ambiente natural quando comparados a sociedade capitalista ${ }^{15}$. Mesmo sem dominar o conceito de desenvolvimento sustentável, como o conhecemos atualmente, os povos quilombolas já praticavam em seus territórios, com a agricultura menos impactante, com o uso dos saberes tradicionais e respeito aos recursos naturais.

No Brasil, as comunidades remanescentes de quilombos eram chamadas de comunidades negras rurais, somente foram reconceituadas e receberam a nomenclatura atual com a Constituição Federal de 1988. Sendo assim, na carta magna brasileira não há menção a negros ou afrodescendentes, mas sim às comunidades remanescentes de quilombo $^{16}$.

11 CLEMENTE, Claudelir Correa; SILVA, José Carlos Gomes da. Dos quilombos à periferia: reflexôes sobre Territorialidades e sociabilidades negras urbanas na Contemporaneidade. Crítica e Sociedade: Revista de Cultura Politica. v. 4, n.1, 2014.

12 MENDONÇA, Leticia Koeppel; TAVIRA, Guilherme; FERREIRA, Everton; LANGE, Roberta; OLIVEIRA, Luana Paré; MOLINA, Caroline; HORA, Karla. A construção de uma política de assistência técnica e extensão rural para superação da extrema pobreza. In: MELLO, Janine. A inclusão produtiva rural no Brasil Sem Miséria: o desafio da superação da pobreza no campo. Brasília: MDS. p. 50-69. 2015.

13 BRASIL. Ministério do Desenvolvimento Social e Combate à Fome. Guia de Políticas Sociais Quilombolas Serviços e beneficios do Ministério do Desenvolvimento Social e Combate à Fome. Brasília, DF, 2009.

14 INSTITUTO DE POLÍTICAS ECONÔMICAS APLICADAS. Politicas agroambientais e sustentabilidade: desafios, oportunidades e liçóes aprendidas. Brasília: Ipea, 2014.

15 SILVESTRE, Diego de Oliveira; MOREIRA, Alecsandra P. da Costa. Uso, vivência e conservação do meio ambiente em populaçóes tradicionais: o caso da comunidade quilombola de Caiana dos Crioulos, Alagoa Grande (PB). Cadernos do Logepa, v. 6, n. 2, p. 180-202, 2011.

16 SALES JR, Ronaldo L. Políticas de Ancestralidade: negritude e africanidade na esfera pública. CAOS - Revista 
Com o intuito de preservar o conhecimento tradicional das comunidades quilombolas, em 13 de abril de 2006 foi editado o Decreto Federal No 5.758, que institui o "Plano Estratégico Nacional de Áreas Protegidas - PNAP", seus princípios, diretrizes, objetivos e estratégias, e abrange as terras indígenas e quilombolas no escopo desta política pública. Pois entende o papel que estes povos desempenham na conservação da biodiversidade e consequentemente, no desenvolvimento do país. A luz da importância deste público, o Ministério do Meio Ambiente (MMA) e demais órgãos ambientais elaboraram legislaçóes mais eficientes e eficazes para a gestão das unidades de conservação e da conservação da biodiversidade em terras indígenas e terras quilombolas ${ }^{17}$.

Um estudo realizado no sul do Brasil analisa a visão de famílias quilombolas em relação à preservação ambiental, observando que apesar de muitas limitaçóes como acesso a informação, baixa escolaridade e renda, as famílias entendem a importância da conservação ambiental e sua estreita relação com a saúde das pessoas. Ainda segundo os autores, os trabalhos frequentes da Assistência Técnica e Extensão Rural contribuem, pois ao realizarem visitas periódicas às famílias, atuam na conscientização da sustentabilidade ambiental ${ }^{18}$.

\section{Quilombolas e as legislaçóes ambientais, vulnerabilidade social e direitos humanos}

No contexto deste trabalho, políticas públicas podem ser entendidas como a ação ou projeto desenvolvido pelo Estado ou pela sociedade civil com vistas a resolver um problema público ${ }^{19}$. Esclarece-se que o objetivo aqui é discutir legislaçóes ambientais que instituem políticas públicas estatais, não serão analisadas as políticas públicas planejadas e executadas pela sociedade civil.

Políticas públicas são ações institucionais necessárias para implantação e consolidação de estratégias para o desenvolvimento rural sustentável das populaçóes excluídas. Uma vez que estimulam a geração de renda e produção de alimentos com qualidade e diversificados, principalmente para agricultores familiares, quilombolas, povos indígenas, assentados, entre outros ${ }^{20}$. Ao observar este dado, é possível concluir que estes atores sociais precisam ser incluídos no escopo das legislaçóes que instituem políticas

Eletrônica de Ciências Sociais. N 14, p. 119 - 133, 2009.

17 BRASIL. Decreto Federal No 5.758, de 13 de abril de 2006. Institui o Plano Estratégico Nacional de Áreas Protegidas - PNAP, seus princípios, diretrizes, objetivos e estratégias, e dá outras providências. Publicação: Diário Oficial da União, 17/04/2006, página 1 (Publicação oficial). Disponível em: http://www.planalto.gov. br/ccivil_03/_Ato2004-2006/2006/Decreto/D5758.htm. Acesso em: 02 ago. 2019

18 MARTINS, Luciana Aparecida Ramos; NISHIJIMA, Toshio. Preservação ambiental e qualidade de vida em comunidades quilombolas. Revista Eletrônica em Gestão, Educação e Tecnologia Ambiental. REGET-CT/ UFSM. n. 1, p. 59-69, 2010.

19 HOFLING, Eloisa de Mattos. Estado e políticas (públicas) sociais. Cadernos Cedes, v. 21, n. 55, p. 30-41, 2001.

20 BRASIL. Ministério do Desenvolvimento Agrário. Política Nacional de Assistência Técnica e Extensão Rural. Brasília, DF, 2004. 
públicas para que tenham condições de produzir alimentos de forma sustentável, além de contribuir para a manutenção do meio ambiente.

Estima-se que a população de povos e comunidades tradicionais esteja em torno de 5 milhóes de famílias e ocupam $1 / 4$ do território nacional ${ }^{21}$. Apesar de ser uma população expressiva, cerca de um milhão de famílias (quilombolas, indígenas, extrativistas e pescadores), vivem em situação de vulnerabilidade social, e necessitam atenção especial dos programas governamentais ${ }^{22}$.

O Decreto Federal No 6.135, de 26 de junho de 2007, dispóe sobre o Cadastro Único (CadÚnico) para Programas Sociais do Governo Federal, cria o instrumento de cadastro das famílias de baixa renda, para possíveis benefícios em programas sociais do governo federal, e que permite identificar as famílias brasileiras de baixa renda. Desse modo, o governo reconhece as reais condiçóes dessas famílias e as seleciona para programas sociais como o Programa Bolsa Família ${ }^{23}$.

O programa federal de transferência de renda, acima citado, beneficiou 129.251 famílias remanescentes de quilombolas no mês de julho de 201924. Quando comparado a setembro de $2009^{25}$, este dado praticamente triplicou, uma das razóes pode ser a Portaria No 376, de 16 de outubro de 2008, que define procedimentos para a gestáo do Cadastro Único para Programas Sociais do Governo Federal, disciplinado pelo Decreto Federal No 6.135, de 26 de junho de 2007. O artigo 25 da referida portaria, orienta o cadastro diferenciado de Povos e Comunidades Tradicionais, este cadastro permite reunir informaçóes de famílias que apresentam características socioculturais e/ou econômicas específicas que demandem formas especiais de cadastramento ${ }^{26}$.

Considerando o exposto, houve um esforço do governo federal, através das legislações que instituem políticas públicas de inclusão social, permitir o reconhecimento através dos instrumentos legais, dos públicos tradicionais e transferir recursos de programas específicos para os municípios que desenvolvem açóes com este público, garantindo assim, a manutenção dos princípios como dignidade e equidade.

21 BRASIL. Ministério do Desenvolvimento Social e Combate à Fome. Guia de Políticas Sociais Quilombolas Serviços e benefícios do Ministério do Desenvolvimento Social e Combate à Fome. Brasília, DF, 2009.

22 BRASIL. Ministério da Cidadania. Relatórios de Informaçôes Sociais. Disponível em: https://aplicacoes.mds.gov. $\mathrm{br} /$ sagi/RIv3/geral/index.php?relatorio=153\&file=entrada\#. Acesso em: 20 set. 2019.

23 BRASIL. Decreto Federal No 6.135, de 26 de junho de 2007. Dispóe sobre o Cadastro Único para Programas Sociais do Governo Federal e dá outras providências. Publicação: Diário Oficial da União - 27/06/2007, página 3 (Publicação oficial). Disponível em: http://www.planalto.gov.br/ccivil_03/_Ato2007-2010/2007/Decreto/ D6135.htm. Acesso em: 11 jun. 2019.

24 BRASIL. Ministério da Cidadania. Relatórios de Informaçôes Sociais. Disponível em: https://aplicacoes.mds.gov. br/sagi/RIv3/geral/index.php?relatorio=153\&file=entrada\#. Acesso em: 20 set. 2019.

25 BRASIL. Ministério do Desenvolvimento Social e Combate à Fome. Guia de Políticas Sociais Quilombolas Serviços e benefícios do Ministério do Desenvolvimento Social e Combate à Fome. Brasília, DF, 2009.

26 BRASIL. Portaria No 376, de 16 de outubro de 2008. Define procedimentos para a gestáo do Cadastro Único para Programas Sociais do Governo Federal, disciplinado pelo Decreto No 6.135, de 26 de junho de 2007. Disponível em: http://www.mds.gov.br/webarquivos/legislacao/bolsa_familia/_doc/portarias/2008/Portaria_ GM_MDS_376_16-10-08-1.pdf. Acesso em: 11 jun. 2019. 


\section{Legislação ambiental brasileira, Política Nacional de Assistência Técnica e Extensão Rural (PNATER) e os povos e comunidades tradicionais}

A Política Nacional de Desenvolvimento Sustentável dos Povos e Comunidades Tradicionais tem por objetivo o desenvolvimento sustentável desses povos, promovendo o fortalecimento e a garantia de direitos territoriais, sociais, ambientais, econômicos e culturais, com respeito e valorização da sua identidade e formas de organizaçáo ${ }^{27}$.

Especificamente o Programa Brasil Quilombola, criado em 2004, orienta açóes de redução de desigualdades sociais e étnicas nos mais variados territórios quilombolas do país. A partir deste programa é possível observar alguns eixos temáticos como: acesso à terra; infraestrutura e qualidade de vida; desenvolvimento local e inclusão produtiva e; direitos e cidadania ${ }^{28}$.

A Fundação Cultural Palmares é responsável pela certificação das comunidades que se autodenominam remanescentes de quilombo, o que lhes dá direito a procedimentos de identificação, delimitação, demarcação e titulação das terras quilombola ${ }^{29}$. Esta certificação é importante, pois sem ela as comunidades quilombolas não acessam programas governamentais específicos, como a demarcação de seus territórios, programas de agricultura familiar que garantam a produção de alimentos com qualidade e diversidade, visando à sustentabilidade das propriedades ou comunidades rurais.

As ações de assistência técnica e extensão rural (ATER), voltadas para a agricultura familiar, trabalham com educação informal, proporcionando conhecimento e a inclusão social da população rural vulnerável. Estas ações são compatíveis com os pressupostos do desenvolvimento sustentável dos povos e comunidades tradicionais. Uma vez que são grupos diferenciados, com cultura e organização social própria e que utilizam o conhecimento e inovaçóes de acordo com as práticas transmitidas pela tradição ${ }^{30}$. Destaca-se ainda que, cabe ao estado garantir a construção da cidadania, apoiar açóes de desenvolvimento endógeno e potencializar o uso sustentável dos recursos naturais e desenvolver processos educativos permanentes e de qualidade, valorizando os atores locais deste processo de desenvolvimento.

Nesse sentido, a integração, que é fundamental para a construção do conceito de sustentabilidade, foi esquecida na construção das legislações que instituem as políticas

27 BRASIL. Decreto No 6.040, de 07 de fevereiro de 2007. Institui a Política Nacional de Desenvolvimento Sustentável dos Povos e Comunidades Tradicionais. Publicação: Diário Oficial da União - 08/02/2007, P 316 (Publicação Original). Disponível em: http://www.planalto.gov.br/ccivil_03/_ato2007-2010/2007/decreto/ d6040.htm. Acesso em: 20 jun. 2019

28 SILVA, André Ricardo Fonsêca da. Políticas Públicas para comunidades quilombolas: uma luta em construção. Revista de Ciências Sociais, Politica e Trabalho, v. 2018, n. 48, p.115-128, 2018.

29 SILVA, André Ricardo Fonsêca da. Políticas Públicas para comunidades quilombolas: uma luta em construção. Revista de Ciências Sociais, Politica e Trabalho, v. 2018, n. 48, p.115-128, 2018.

30 BRASIL. Ministério do Desenvolvimento Agrário. Política Nacional de Assistência Técnica e Extensão Rural. Brasília, DF, 2004. 
públicas brasileiras que visam o desenvolvimento agropecuário. Pois, por um lado se pensava no desenvolvimento agropecuário, de outro se discutia a política ambiental como antagonista daquele, gerando ações conflituosas nesta área ${ }^{31}$.

No início dos anos 2000, enquanto o país vivia um momento de abertura à participação e ao controle social, se retomou a discussão acerca da assistência técnica e extensão rural. Esta, voltada para agricultores familiares, assentados, quilombolas, pescadores artesanais e povos indígenas. Tendo como elemento principal a inclusão social e produtiva das populaçôes rurais supracitadas ${ }^{32}$.

A Política Nacional de Assistência Técnica e Extensão Rural (PNATER) foi instituída pela Lei Federal No 12.188, de 11 de janeiro de 2010 e tem por objetivo contribuir para a implantação de desenvolvimento sustentável, por meio da produção de alimentos e sua comercialização, estimulando a agroindustrialização e geração de renda nas pequenas propriedades, a partir da realidade local ${ }^{33}$.

Cabe salientar que a PNATER prevê um trabalho educativo multidisciplinar envolvendo vários entes de ATER, com metodologias participativas, construtivista e humanista, partindo da realidade e do conhecimento local. Assim sendo as ações no meio rural devem fortalecer a participaçáo popular e atender as diferenças regionais, a pluralidade e diversidade social, econômica e ambiental existente no território ${ }^{34}$.

Com base na PNATER busca-se trabalhar práticas diversificadas e sustentáveis de produção. Diferente da agricultura convencional que preconiza em sua prática a produtividade e o lucro, a agricultura agroecológica tem como base o desenvolvimento sustentável, o qual observa a permanência das famílias no meio rural, valorizando os saberes locais e a autonomia dos povos e comunidades tradicionais e agricultores familiares. Ainda, observa-se a utilização de práticas de manejo de solo, de conservação dos recursos naturais e de reconhecimento das características culturais e modo de vida ${ }^{35}$.

Apesar de a agricultura familiar ser fundamental para a produção de alimentos diversificados, estima-se que $1 / 4$ da população brasileira que vive no meio rural está em situação de vulnerabilidade social - extrema pobreza, este número é cinco vezes maior para a população rural do que comparado com a população que vive nas cidade $^{36}$.

31 INSTITUTO DE POLÍTICAS ECONÔMICAS APLICADAS. Politicas agroambientais e sustentabilidade: desafios, oportunidades e liçóes aprendidas.

32 BRASIL. Ministério do Desenvolvimento Agrário. Política Nacional de Assistência Técnica e Extensáo Rural. Brasília, DF, 2004.

33 BRASIL. Ministério do Desenvolvimento Agrário. Política Nacional de Assistência Técnica e Extensão Rural. Brasília, DF, 2004.

34 BRASIL. Ministério do Desenvolvimento Agrário. Política Nacional de Assistência Técnica e Extensão Rural. Brasília, DF, 2004.

35 SANTOS, Christiane Fernandes Dos; SIQUEIRA, Elisabete Stradiotto; ARAÚJO, Iriane Teresa De; MAIA, Zildenice Matias Guedes.A agroecologia como perspectiva de sustentabilidade na agricultura familiar. Ambiente \& Sociedade. São Paulo, v. 17, n. 2, p. 33-52, 2014.

36 MENDONÇA, Leticia Koeppel; TAVIRA, Guilherme; FERREIRA, Everton; LANGE, Roberta; OLIVEIRA, Luana Paré; MOLINA, Caroline; HORA, Karla. A construção de uma política de assistência técnica e extensão 
Consequência disto são as pequenas áreas para produção, associadas a problemas estruturais de qualidade de solo, além de grandes distâncias da sede dos municípios, levando as comunidades rurais a situaçóes de invisibilidade social aos entes públicos, contribuindo para a inexistência de serviços básicos da assistência social, educação, saúde, saneamento, entre outros ${ }^{37}$.

Esta situação contribui para que o percentual de vulnerabilidade social seja mais grave no meio rural, que se associa à situação da insegurança alimentar das famílias e a pobreza, sendo potencializadas pelo gênero, raça, etnia e geraçáo, concentrando os altos índices em regióes com povos indígenas e comunidades remanescentes de quilombos ${ }^{38}$.

Neste contexto, percebe-se a necessidade das legislaçôes que instituem as políticas públicas envolverem os territórios tradicionais que são espaços próprios à reprodução cultural, social e econômica dos povos e comunidades tradicionais. Observando assim, as legislaçóes que instituem as políticas públicas contemplam o desenvolvimento sustentável, o acesso aos territórios tradicionais e aos recursos naturais, infraestrutura, inclusão social, fomento e produção sustentável, e como buscam assegurar a autonomia sociopolítica e econômica dos povos e comunidades tradicionais ${ }^{39}$.

A Lei Federal No 6.938 de 31 de agosto de 1981, que dispóe sobre a Política Nacional do Meio Ambiente é considerada o marco da legislaçáo ambiental brasileira. Esta política tem por objetivo a preservação, melhoria e qualidade ambiental e o equilíbrio ecológico, porém náo contempla povos e comunidades tradicionais no escopo da legislação ${ }^{40}$. Entretanto, a Lei No 10.165, de 27 de dezembro de 2000, que altera a Lei Federal No 6.938, faz referência às Comunidades Tradicionais, condicionando a isenção de pagamento de taxas de controle e fiscalização ambiental para estas, que estão ocupando os seus territórios com atividades extrativistas dos recursos naturais ${ }^{41}$.

Percebe-se que anterior à Constituição Federal de 1988, os povos e comunidades tradicionais eram invisíveis às legislaçóes ambientais. Apesar de existir a lei de criação da política de meio ambiente, a mesma ganhou força somente a partir da década de 1990, com as seguidas discussóes acerca das questóes ambientais, impulsionadas pela

rural para superação da extrema pobreza. In: MELLO, Janine. A inclusão produtiva rural no Brasil Sem Miséria: o desafio da superaçáo da pobreza no campo. Brasília: MDS. p. 50-69. 2015.

37 ASSOCIAÇÃO SULINA DE CRÉDITO E ASSISTÊNCIA RURAL (ASCAR/RS - EMATER). Plano de trabalho do projeto piloto. 2017.

38 ASSOCIAÇÃO SULINA DE CRÉDITO E ASSISTÊNCIA RURAL (ASCAR/RS - EMATER). Plano de trabalho do projeto piloto. 2017.

39 BRASIL. Ministério do Desenvolvimento Social e Combate à Fome. Guia de Políticas Sociais Quilombolas Serviços e benefícios do Ministério do Desenvolvimento Social e Combate à Fome. Brasília, DF, 2009.

40 BRASIL. Lei Federal No 6.938 de 31 de agosto de 1981. Dispóe sobre a Política Nacional do Meio Ambiente, seus fins e mecanismos de formulação e aplicação, e dá outras providências. Disponível em: http://www.planalto.gov. br/ccivil_03/Leis/L6938.htm. Acesso em: 10 Jul. 2019

41 BRASIL. Lei Federal No 10.165, de 27 de dezembro de 2000. Altera a Lei no 6.938, de 31 de agosto de 1981, que dispóe sobre a Política Nacional do Meio Ambiente, seus fins e mecanismos de formulação e aplicação, e dá outras providências. Disponível em: http://www.planalto.gov.br/ccivil_03/Leis/L10165.htm. Acesso em: 12 jul. 2019. 
preocupação das autoridades mundiais frente ao desenvolvimento econômico e social, sem comprometer o meio ambiente. A Rio 92, como ficou conhecida a Conferência das Naçóes Unidas para o Meio Ambiente e o Desenvolvimento, obteve como resultados: a criação da Conservação da Biodiversidade e Mudanças Climáticas - Protocolo de Kyoto, a Declaraçáo do Rio e a Agenda $21^{42}$.

A Agenda 21 teve por objetivo compor um plano de açáo para a sociedade sustentar a vida no planeta no século XXI, seguindo o princípio de "pensar globalmente, agir localmente" ${ }^{\prime 3}$. No mesmo sentido, a Agenda 2030 traz como objetivos, dentre outros: acabar com a pobreza em todas as suas formas, em todos os lugares; acabar com a fome, alcançar a segurança alimentar e melhoria da nutrição e promover a agricultura sustentável; alcançar a igualdade de gênero e empoderar todas as mulheres e meninas; reduzir a desigualdade dentro dos países e entre eles; assegurar padróes de produçấo e de consumo sustentáveis, sendo grandes desafios mundiais para a promoçáo do desenvolvimento sustentável ${ }^{44}$.

Um dos compromissos da Agenda 21 foi à educação ambiental (EA), sendo uma importante ferramenta para a conservaçáo do meio ambiente, que emerge dos movimentos ambientalistas e sociais na redemocratização do país, a partir da sensibilização dos indivíduos acerca das questôes ambientais. A regulamentação da educaçáo ambiental ocorreu somente em 1999 com a criaçáo da Lei Federal No 9.795, de 27 de abril, que instituiu a Política Nacional de Educação Ambiental, a qual prevê o incentivo à sensibilização ambiental das populações tradicionais, por meio da educação não formal ${ }^{45}$. Em 2005 foi criado o Programa Nacional de Educação Ambiental, estabelecendo a EA formal para o sistema educacional brasileiro, tendo como um dos públicos às comunidades quilombolas, trazendo a perspectiva da sustentabilidade ambiental na construção de um país de todos ${ }^{46}$.

Nesse sentido, é importante destacar que o desenvolvimento sustentável dos povos tradicionais está intimamente ligado à educaçáo ambiental e às dimensôes ambientais, sociais e econômicas, incluindo também a dimensão institucional, a política, a cultural e a ecológica ${ }^{47}$. Assim sendo, o conceito de sustentabilidade leva em consideração o

42 NASCIMENTO, Elimar Pinheiro do. Trajetória da Sustentabilidade: do ambiental ao social, do social ao econômico. Estudos Avançados, v. 26, n. 74, p. 51-64, 2012.

43 CONFERÊNCIA DAS NAÇÕES UNIDAS SOBRE MEIO AMBIENTE E DESENVOLVIMENTO (CNUMAD). Agenda 21. São Paulo: Secretaria de Estado do Meio Ambiente, 1992.

44 ORGANIZAÇÃO DAS NAÇÕES UNIDAS. A Agenda 2030 para o Desenvolvimento Sustentável. 2015. Disponível em: https://nacoesunidas.org/pos2015/agenda2030/. Acesso em: 01 Out. 2019

45 BRASIL. Lei Federal No 9.795, de 27 de abril de 1999. Dispóe sobre a educação ambiental, institui a Política Nacional de Educação Ambiental e dá outras providências. Disponível em: http://www.planalto.gov.br/ ccivil_03/leis/19795.htm. Acesso em: 01 jul. 2019

46 BRASIL. Ministério do Meio Ambiente. Ministério da Educação. Programa Nacional de Educação Ambiental. ProNEA. 3a ediçấo. Brasília: Ediçôes MMA. 2005.

47 FROEHLICH, Cristiane. Sustentabilidade: dimensões e métodos de mensuração de resultados. DESENVOLVE: Revista de Gestão do Unilasalle, Canoas, v. 3, n. 2, p. 151-168, 2014 
crescimento econômico com a manutenção do meio ambiente, através da utilização equilibrada dos recursos naturais, além da justiça social e desenvolvimento humano ${ }^{48}$.

O modelo de desenvolvimento sustentável fruto do relatório de Brundtland, difundido na Rio 92, busca a proteção dos recursos naturais, a equidade econômica e a justiça social, onde o meio ambiente náo é somente uma fonte de recursos que podem ser utilizados pelo homem de forma irracional ${ }^{49}$.

A EA está relacionada com a representação social, uma vez que, através da educação os sujeitos são capazes de transformar suas vidas e por consequência o meio que vivem ${ }^{50}$. Neste contexto, a EA não pode ser algo fechado, mas precisa contribuir para o sujeito ser protagonista no processo educativo ${ }^{51}$.

Com isso, as legislaçóes ambientais sobre as políticas públicas voltadas para a sustentabilidade preconizam os agricultores familiares e os povos e comunidades tradicionais, por serem grupos que apresentam em seus traços culturais a conservação da biodiversidade, o uso sustentável dos recursos naturais e o equilíbrio ecológico. Neste contexto, a Política Nacional da Biodiversidade, instituída pelo Decreto Federal No 4.339, de 22 de agosto de 2002, rege os princípios da conservação da biodiversidade, através do uso sustentável dos recursos naturais, do valor intrínseco associado à manutenção da diversidade cultural nacional e o conhecimento tradicional ligado à biodiversidade ${ }^{52}$.

A aprovação desta política é algo a ser destacado, pois o trâmite nas duas casas legislativas federais durou cerca de oito anos. Além de ocorrer em um clima de batalha, pois dois projetos substitutivos foram apresentados pelos ambientalistas, conservacionistas, ruralistas, mobilizando a imprensa e o terceiro setor (especialmente as Organizaçóes NãoGovernamentais - ONGs), isso devido aos lobbies que existem no congresso, cada um em defesa de suas posiçóes e a forma de cada um ver a proteção do meio ambiente ${ }^{53}$.

48 BANERJEE, Subhabrata B. Organisational strategies for sustainable development: developing a research agenda for the new Millennium. Australian Journal of Management, v. 27, n. 1, p. 105-117, 2002.

49 SOARES, Ilton Araújo. Sustentabilidade socioambiental e efetividade de gestão de unidades de conservação. 2019. 219 f. Tese (Doutorado em Desenvolvimento e Meio Ambiente) - Centro de Biociências, Programa de PósGraduação em Desenvolvimento e Meio Ambiente, Universidade Federal do Rio Grande do Norte. Natal, RN, 2019.

50 LAYRARGUES, Philippe Pomier. Educação ambiental com compromisso social: o desafio da superação das desigualdades. IN: LOUREIRO, Carlos Frederico Bernardo; LAYRARGUES, Philippe Pomier; CASTRO, Ronaldo de Souza (Orgs.). Repensar a Educação Ambiental: um olhar crítico. São Paulo: Cortez. p. 11-31. 2009.

51 BOFF, Leonardo. Sustentabilidade: o que é: o que não é. 5 ed. Petrópolis: Vozes, 2016.

52 BRASIL. Decreto Federal No 4.339, de 22 de agosto de 2002. Institui princípios e diretrizes para a implementação da Política Nacional da Biodiversidade. Publicação: Diário Oficial da União - 23/08/2002, página 2 (Publicação Original). Disponível em: http://www.planalto.gov.br/ccivil_03/decreto/2002/D4339.htm. Acesso em: 20 jul. 2019.

53 MEDEIROS, Rodrigo. Singularidades do sistema de áreas protegidas para a conservação e uso da biodiversidade brasileira. In: GARAY, Irene; BECKER, Bertha (orgs.). Dimensóes Humanas da Biodiversidade. Petrópolis: Editora Vozes. p. 159-184. 2006. 
Assim, esta política traz os conceitos amplamente discutidos na Conferência das Naçôes Unidas sobre a conservação da biodiversidade e em relação ao reconhecimento dos povos e comunidades tradicionais como atores principais no processo de conservação. Além de discutir a utilização sustentável dos recursos naturais, neste caso, os conhecimentos tradicionais são objetos de estudos em pesquisas científicas ${ }^{54}$.

No que diz respeito à posse da terra, a Lei Federal No 4.504, de 30 de novembro de 1964, que "Dispóe sobre o Estatuto da Terra, e dá outras providências", em seu artigo $9^{\circ}$ traz as seguintes consideraçóes: terras de domínio público que são de propriedade da União, para serviços ou obras de qualquer natureza e as devolutas da União, dos Estados e dos Municípios; terras particulares e as passíveis de reforma agrária para a promoção da justiça social, do bem estar no meio rural e desenvolvimento econômico ${ }^{55}$.

As terras de domínio público vêm sendo motivo de preocupação no que tange aos povos e comunidades tradicionais, que utilizam terras coletivas e com uso regulamentado em normas específicas. A Lei Federal No 11.952 de 25 de junho de 2009, que dispóe sobre a regularização fundiária das ocupaçôes incidentes em terras situadas em áreas da União, no âmbito da Amazônia Legal, afirma que não são passíveis de alienação ou concessão de direito de uso ${ }^{56}$. Contrapondo a isso, em 2017 ocorreu a implementação da Lei Federal No 13.465, a qual é reconhecida por muitos ambientalistas como a "Lei da Grilagem". Esta lei facilita e de certa maneira, incentiva a destruição da floresta amazônica, uma vez que regulariza as áreas de até 2.500 hectares, ocupadas mediante alienação e não mais 1.500 hectares como previa a lei anterior. Esta combinação associada ao novo limite temporal de comprovaçáo de utilizaçáo da terra; e os preços baixos fixados para alienação, que incentiva a invasăo de novas áreas, o que gera conflitos com as comunidades tradicionais que não tenham seus territórios reconhecidos ${ }^{57}$.

Através do Decreto No 6.874, de 05 de junho de 2009, foi instituído o Programa de Manejo Florestal Comunitário e Familiar (PMFC), com os princípios de fomentar açôes e gestáo para o manejo sustentável das florestas habitadas pelas comunidades tradicionais e agricultores familiares, que extraem da floresta o seu sustento. O PMFC tem por objetivos entre outros, promover desenvolvimento sustentável, a geração de

54 BRASIL. Decreto Federal No 4.339, de 22 de agosto de 2002. Institui princípios e diretrizes para a implementação da Política Nacional da Biodiversidade. Publicação: Diário Oficial da União - 23/08/2002, página 2 (Publicação Original). Disponível em: http://www.planalto.gov.br/ccivil_03/decreto/2002/D4339.htm. Acesso em: 20 jul. 2019.

55 BRASIL. Lei Federal No 4.504, de 30 de novembro de 1964. Dispóe sobre o Estatuto da Terra, e dá outras providências. Disponível em: http://www.planalto.gov.br/ccivil_03/leis/l4504.htm. Acesso em: 23 Set. 2019.

56 BRASIL. Lei Federal No 11.952 de 25 de junho de 2009. Dispóe sobre a regularizaçáo fundiária das ocupaçóes incidentes em terras situadas em áreas da Uniáo, no âmbito da Amazônia Legal; altera as Leis nos 8.666, de 21 de junho de 1993, e 6.015, de 31 de dezembro de 1973; e dá outras providências. Disponível em: http://www. planalto.gov.br/ccivil_03/_Ato2007-2010/2009/Lei/L11952.htm. Acesso em: 23 Set. 2019.

57 MORAIS, Henrique Michael Andreetta de Oliveira Matos de. Regularizą̧ão Fundiária Rural na Amazônia Legal: Uma análise da Lei №13.465 de 11 de julho de 2017. 2017. 58 f. Monografia (Graduação em Direito) - Faculdade de Direito, Universidade de Brasília, Brasília - Distrito Federal, 2017. 
trabalho e renda para as famílias, a valorização das formas diferentes de organização social, cultural e produtiva, a regularização da posse e do uso das áreas ocupadas nas florestas da União, a promoção de assistência técnica e extensão rural adaptadas ao manejo florestal comunitário e familiar e a promoção da educação ambiental em todos os níveis ${ }^{58}$.

Sáo considerados entraves, que devem ser superados para tornar o programa uma alternativa eficiente de preservaçáo do Meio Ambiente com a exploraçáo sustentável das florestas, garantido renda e dignidade para as famílias envolvidas: a ausência de regularização fundiária, a dificuldade de aprovação dos planos de manejo, inexistência ou ineficiência de linhas de crédito específicas, a baixa oferta de assistência técnica especializada e a reduzida escala de produção ${ }^{59}$.

Por outro lado as comunidades tradicionais tem o "conhecimento tradicional associado" protegido através da Lei No 13.123, de 20 de maio de 2015, que reconhece as práticas conservacionistas e uso sustentável da biodiversidade no cotidiano das comunidades tradicionais. Esta Lei assegura em esfera nacional a participação nas tomadas de decisões dos assuntos relacionados a conservação da biodiversidade e o uso sustentável de seus conhecimentos tradicionais associados ao patrimônio genético do País ${ }^{60}$.

A agricultura e a pecuária, estáo diretamente ligadas aos processos de desmatamento no Brasil ${ }^{61}$. Em relatório divulgado pela Organização das Naçôes Unidas (ONU), entre os anos de 1900 e 2005, mais de $80 \%$ do desflorestamento foram causados por estas atividades $^{62}$.

O Código Florestal de 1965, mantinha certa rigidez em relação ao uso dos recursos naturais, às áreas de preservação permanente (APP’s) e às reservas legais (RL), que são considerados essenciais à proteção das florestas brasileiras. Mesmo assim, crimes ambientais eram cometidos sem a devida punição ${ }^{63}$.

58 BRASIL. Decreto Federal No 6.874 de 05 de junho de 2009. Institui, no âmbito dos Ministérios do Meio Ambiente e do Desenvolvimento Agrário, o Programa Federal de Manejo Florestal Comunitário e Familiar - PMCF, e dá outras providências. Publicação: Diário Oficial da União - 08/06/2009, página 1, (Publicação Original). Disponível em: http://www.planalto.gov.br/ccivil_03/_ato2007-2010/2009/decreto/d6874.htm. Acesso em: 30 Set. 2019.

59 BRASIL. Ministério do Meio Ambiente. Serviço Florestal Brasileiro. Programa Federal de manejo florestal comunitário e familiar. 2016. Disponível em: http://www.florestal.gov.br/florestas-comunitarias/68-fomentoflorestal/602-programa-federal-de-manejo-florestal-comunitario-e-familiar. Acesso em: 02 Out. 2019.

60 BRASIL. Lei Federal No 13.123, de 20 de maio de 2015. Regulamenta o inciso II do $\$ 1^{\circ}$ e o $\$ 4^{\circ}$ do art. 225 da Constituição Federal, o Artigo 1, a alínea j do Artigo 8, a alínea c do Artigo 10, o Artigo 15 e os $\$ \$ 3^{\circ}$ e $4^{\circ}$ do Artigo 16 da Convenção sobre Diversidade Biológica, promulgada pelo Decreto No 2.519, de 16 de março de 1998; dispóe sobre o acesso ao patrimônio genético, sobre a proteção e o acesso ao conhecimento tradicional associado e sobre a repartição de benefícios para conservação e uso sustentável da biodiversidade; revoga a Medida Provisória No 2.186-16, de 23 de agosto de 2001; e dá outras providências. Disponível em: http://www. planalto.gov.br/ccivil_03/_ato2015-2018/2015/lei/113123.htm. Acesso em: 30 Set. 2019.

61 FEISTAUER, Diogo; LOVATO Paulo Emilio; SIMINSKI, Alexandre; RESENDE, Sidivan Aparecido. Impactos do novo código florestal na regularização ambiental de propriedades rurais familiares. Ciência Florestal, Santa Maria, v. 24, n. 3, p. 749-757, 2014.

62 ORGANIZAÇÃO DAS NAÇÓES UNIDAS. FAO: pastoreio causou 80\% do desflorestamento no Brasil entre 1990-2005. 2016. Disponível em: https://nacoesunidas.org/fao-pastoreio-causou-80-do-desflorestamento-nobrasil-entre-1990-2005/. Acesso em: 01 Out. 2019.

63 RORIZ, Pedro Augusto Costa; FEARNSIDE, Philip Martin. A construção do Código Florestal Brasileiro e as diferentes perspectivas para a proteção das florestas. Novos Cadernos NAEA. v. 18, n. 2, p. 51-68, 2015. 
As investidas em tornar a legislação ambiental pertinente a proteção das áreas verdes mais rígida não agradavam os grandes proprietários rurais, levando ao fortalecimento da bancada ruralista do Congresso Nacional. Depois de muitos projetos, propostas e medidas provisórias engavetadas, em 2012 surgiu o Novo Código Florestal, instituído pela Lei Federal No 12.651, revogando o Código Florestal de 1965, que outrora pesquisadores e juristas consideravam um importante instrumento de proteção ambiental, sem necessidade de alteraçôes ${ }^{64}$. Além disso, o Novo Código Florestal também surgiu com o intuito de "legalizar as irregularidades".

O mais Novo Código Florestal apresenta muitas açóes consideradas desfavoráveis ao meio ambiente. Se destacando a alteração dos critérios técnicos para definição de APP e RL, a anistia da responsabilidade ambiental nas três esferas (administrativa, criminal e civil) e a instituição de um mercado de pagamento por serviços ambientais no Brasil. A nova proposta altera as regras de proteçáo ambiental, quanto a RL e APP, traz no escopo da lei, a pequena propriedade rural, a utilidade pública, o interesse social, as atividades eventuais ou de baixo impacto ambiental e a incorporação de dois instrumentos, o Cadastro Ambiental Rural (CAR) e o Programa de Regularização Ambiental ${ }^{65}$.

Levando em consideração que as atividades quilombolas quando realizadas segundo os usos, costumes e tradiçóes são de baixo impacto na natureza, O Novo Código Florestal considera estes em uma nova categoria, "as atividades eventuais ou de baixo impacto ambiental”. Neste sentido, o instrumento CAR tem caráter protetivo, mesmo quando a comunidade quilombola não tem o processo de demarcação fundiária concluída ${ }^{66}$.

Assim como as comunidades tradicionais têm formas de uso de terras segundo suas tradições, há a possibilidade de entendimento do Novo Código Florestal destas comunidades como "pequenas propriedades rurais". Desta forma, os órgãos ambientais podem não reconhecer as particularidades das comunidades tradicionais na interpretação da lei, o que muitas vezes pode gerar conflitos, injustiças e desrespeito aos direitos culturais ${ }^{67}$.

Por fim, analisando as manifestações sociais, a interpretação da comunidade científica, comprometida com o meio ambiente, e as inconstitucionalidades apresentadas na lei fica evidente que os pequenos agricultores familiares e as comunidades tradicionais,

64 RORIZ, Pedro Augusto Costa; FEARNSIDE, Philip Martin. A construção do Código Florestal Brasileiro e as diferentes perspectivas para a proteção das florestas. Novos Cadernos NAEA. v. 18, n. 2, p. 51-68, 2015.

65 BRASIL. Lei Federal No 12.651 de 20 de maio de 2012. Dispôe sobre a proteção da vegetação nativa; altera as Leis $\mathrm{No}_{s}$ 6.938, de 31 de agosto de 1981, 9.393, de 19 de dezembro de 1996, e 11.428, de 22 de dezembro de 2006; revoga as Leis $\mathrm{No}_{\mathrm{S}}$ 4.771, de 15 de setembro de 1965, e 7.754, de 14 de abril de 1989, e a Medida Provisória No 2.166-67, de 24 de agosto de 2001; e dá outras providências. Disponível em: http://www. planalto.gov.br/ ccivil_03/_Ato2011-2014/2012/Lei/L12651.htm. Acesso em: 30 Set. 2019.

66 FEISTAUER, Diogo; LOVATO Paulo Emilio; SIMINSKI, Alexandre; RESENDE, Sidivan Aparecido. Impactos do novo código florestal na regularização ambiental de propriedades rurais familiares. Ciência Florestal, Santa Maria, v. 24, n. 3, p. 749-757, 2014.

67 FEISTAUER, Diogo; LOVATO Paulo Emilio; SIMINSKI, Alexandre; RESENDE, Sidivan Aparecido. Impactos do novo código florestal na regularização ambiental de propriedades rurais familiares. Ciência Florestal, Santa Maria, v. 24, n. 3, p. 749-757, 2014. 
não foram os principais beneficiados pelas alteraçóes. Por outro lado, os grandes proprietários rurais que cometeram diversas violaçóes ambientais, buscaram a anistia com a utilização deste instrumento legal.

Outro momento importante para as comunidades tradicionais foi à instituição do Conselho Nacional dos Povos e Comunidades Tradicionais (CNPCT), de caráter consultivo, através do Decreto federal No 8.750, de 09 de maio de 2016, que "Institui o Conselho Nacional dos Povos e Comunidades Tradicionais”. A criação deste conselho deu voz e vez para as comunidades participarem das discussóes, convençóes, acordos e tratados com o governo federal, além de fortalecer as lutas pelos espaços territoriais, os direitos socioambientais, econômicos e culturais ${ }^{68}$. A composiçáo do conselho se dá por edital de eleição para 29 representantes da sociedade civil, representando todos os segmentos dos PCT, 15 representantes da esfera federal, indicados pelas autoridades máximas de cada órgão e dois convidados permanentes do Ministério Público Federal ${ }^{69}$.

Apesar de ser um importante mecanismo de defesa e garantia de direitos destas comunidades, o tão jovem Conselho, que mal instituído, sofreu sançóes do governo federal. Primeiro pelo abandono federal, logo após a publicação do decreto, demonstrando pouco caso com as políticas afirmativas. Segundo pela imposição da bancada ruralista que, mais uma vez, incomodada com a Política Nacional de Desenvolvimento Sustentável de Povos e Comunidades Tradicionais, propôs ao Governo Temer a revogação do Decreto Federal No 6.040/2007. E no atual governo federal, o Decreto Federal No 9.759, de 11 de abril de 2019, que estabelece a "extinção e estabelecimento de regras e limitaçóes para colegiados da administraçáo pública federal”, que mostra a intenção em dificultar a participação social e popular nos espaços representativos ${ }^{70}$, dificultando assim o acesso aos direitos sociais fruto de muitos anos de lutas.

\section{Consideraçóes finais}

As legislações que instituem as políticas públicas para os povos e comunidades tradicionais estão intimamente ligadas às de sustentabilidade ambiental. Assim, estas legislaçóes voltadas ao meio ambiente e às comunidades tradicionais somente foram impulsionadas e consolidaram-se após a redemocratização do país, com a Constituição Federal e com a criação de normativas. Os movimentos sociais são responsáveis pela

68 BRASIL. Decreto Federal No 8.750, de 09 de maio de 2016. Institui o Conselho Nacional dos Povos e Comunidades Tradicionais. Publicação: Diário Oficial da União - 10/05/2016, página 1 (Publicaçáo Original). Disponível em: http://www.planalto.gov.br/ccivil_03/_Ato2015-2018/2016/Decreto/D8750.htm. Acesso em: 30 Set. 2019.

69 BRASIL. Decreto Federal No 8.750, de 09 de maio de 2016. Institui o Conselho Nacional dos Povos e Comunidades Tradicionais. Publicação: Diário Oficial da União - 10/05/2016, página 1 (Publicação Original). Disponível em: http://www.planalto.gov.br/ccivil_03/_Ato2015-2018/2016/Decreto/D8750.htm. Acesso em: 30 Set. 2019.

70 MINISTÉRIO PÚBLICO FEDERAL. Nota Técnica No 02/2019/ASSREV-1a CCR. 2019. Disponível em: http://www.mpf.mp.br/pgr/documentos/nota-tecnica-no-02-2019-reflexoes-sobre-o-decreto-9759-19-v3.pdf. Acesso em: 02 Out. 2019. 
propulsão destas regulamentaçóes, reivindicavam posicionamento do poder público e melhores condições de vida para a população.

A Política Nacional de Desenvolvimento Sustentável dos Povos e Comunidades Tradicionais mostrou para o país a importância histórico-cultural e social que estes povos e comunidades tem para o país. Assim, como merece o reconhecimento da sociedade brasileira, uma vez que sofreram por longos períodos com a escravatura, com a dominaçáo europeia e com situaçốes de trabalho em condições desumanas.

A jovem democracia brasileira náo deu conta de reparar as injustiças que esses povos sofreram no processo de desenvolvimento do país e a legislação que protegia estes povos tem um curto espaço temporal e o que vemos hoje é uma tentativa de muitas frentes ruralistas acabarem com os direitos conquistados, principalmente no que tange o assunto demarcação territorial, esse retrocesso nas políticas afirmativas estão tornando-os novamente invisíveis.

Apesar de estar disponível uma ampla legislação ambiental que institui políticas públicas para as comunidades quilombolas, não significa que estas regulamentaçóes estejam implementadas e contribuindo para a proteçáo destas comunidades. Desta forma, as conquistas dos povos e comunidades tradicionais náo se deram por acaso, são frutos de muitas lutas dos movimentos sociais e ambientais que encontram inúmeras dificuldades e entraves. Dentre estes pode-se citar a resistência dos poderes governamentais que discutem políticas a partir de corporativismo e do capital econômico.

O objetivo do estudo foi alcançado, pois foi possível realizar a análise da legislação ambiental brasileira quanto aos povos e comunidades tradicionais. Uma vez que, foram encontradas legislaçóes específicas para comunidades quilombolas e nas demais legislaçóes ambientais, estas estão contempladas, em especial no que diz respeito à conservação das florestas, à biodiversidade e ao desenvolvimento sustentável. Além do saber tradicional associado ao patrimônio genético preservado.

Esta pesquisa apresenta contribuições importantes para o campo do saber, pois as legislaçôes que instituem as políticas públicas voltadas para a sustentabilidade preconizam os agricultores familiares e os povos e comunidades tradicionais, por serem grupos que apresentam em seus traços culturais a conservação da biodiversidade, o uso sustentável dos recursos naturais e o equilíbrio ecológico. E atualmente é possível notar que as regulamentaçôes legais de preservação ambiental se constituíram pela forma como estes povos e comunidades se relacionam com a terra, e não como os colonizadores que aqui chegaram e buscaram apenas a exploração dos bens naturais. Associada a pressốes de organismos internacionais, como a ONU. Assim, os povos e os organismos internacionais conferem papel importante em relação aos aspectos conservacionistas.

A limitação deste estudo encontra-se na busca pela legislação ambiental específica, sendo por tanto interessante realizar pesquisas de campo com os povos e comunidades 
tradicionais, com os gestores de políticas públicas e com os legisladores, para verificar como estes povos convivem com estas políticas e como elas afetam seus cotidianos. Tornase importante que novos estudos nesta área sejam fomentados e ocorram em todo o país.

\section{Referências}

ASSOCIAÇÃO SULINA DE CRÉDITO E ASSISTÊNCIA RURAL (ASCAR/RS EMATER). Plano de trabalho do projeto piloto. 2017.

ASSOCIAÇÃO SULINA DE CRÉDITO E ASSISTÊNCIA RURAL (ASCAR/RS EMATER). A natureza socioassistencial das açôes desenvolvidas pela ASCAR-EMATER/ RS no meio rural. Porto Alegre, RS, 2016.

BANERJEE, Subhabrata B. Organisational strategies for sustainable development: developing a research agenda for the new Millennium. Australian Journal of Management, v. 27, n. 1, p. 105-117, 2002.

BOFF, Leonardo. Sustentabilidade: o que é: o que não é. 5 ed. Petrópolis: Vozes, 2016.

BRASIL. Decreto Federal No 6.040, de 07 de fevereiro de 2007. Institui a Política Nacional de Desenvolvimento Sustentável dos Povos e Comunidades Tradicionais. Publicação: Diário Oficial da União - 08/02/2007, P 316 (Publicação Original). Disponível em: http://www.planalto.gov.br/ccivil_03/_ato2007-2010/2007/decreto/ d6040.htm. Acesso em: 20 jun. 2019

BRASIL. Decreto Federal No 6.135, de 26 de junho de 2007. Dispóe sobre o Cadastro Único para Programas Sociais do Governo Federal e dá outras providências. Publicação: Diário Oficial da União - 27/06/2007, página 3 (Publicação oficial). Disponível em: http://www.planalto.gov.br/ccivil_03/_Ato2007-2010/2007/Decreto/D6135.htm. Acesso em: 11 jun. 2019.

BRASIL. Decreto Federal No 4.339, de 22 de agosto de 2002. Institui princípios e diretrizes para a implementação da Política Nacional da Biodiversidade. Publicação: Diário Oficial da União - 23/08/2002, página 2 (Publicação Original). Disponível em: http://www. planalto.gov.br/ccivil_03/decreto/2002/D4339.htm. Acesso em: 20 jul. 2019.

BRASIL. Decreto Federal No 5.758, de 13 de abril de 2006. Institui o Plano Estratégico Nacional de Áreas Protegidas - PNAP, seus princípios, diretrizes, objetivos e estratégias, e dá outras providências. Publicação: Diário Oficial da União, 17/04/2006, página 1 (Publicação oficial). Disponível em: http://www.planalto.gov.br/ccivil_03/_Ato20042006/2006/Decreto/D5758.htm. Acesso em: 02 ago. 2019

BRASIL. Decreto Federal No 6.874 de 05 de junho de 2009. Institui, no âmbito dos Ministérios do Meio Ambiente e do Desenvolvimento Agrário, o Programa Federal de Manejo Florestal Comunitário e Familiar - PMCF, e dá outras providências. Publicação: 
Diário Oficial da União - 08/06/2009, página 1, (Publicação Original). Disponível em: http://www.planalto.gov.br/ccivil_03/_ato2007-2010/2009/decreto/d6874.htm. Acesso em: 30 Set. 2019.

BRASIL. Decreto Federal No 8.750, de 09 de maio de 2016. Institui o Conselho Nacional dos Povos e Comunidades Tradicionais. Publicação: Diário Oficial da União 10/05/2016, página 1 (Publicação Original). Disponível em: http://www.planalto.gov. br/ccivil_03/_Ato2015-2018/2016/Decreto/D8750.htm. Acesso em: 30 Set. 2019.

BRASIL. Lei Federal No 10.165, de 27 de dezembro de 2000. Altera a Lei no 6.938, de 31 de agosto de 1981, que dispóe sobre a Política Nacional do Meio Ambiente, seus fins e mecanismos de formulação e aplicação, e dá outras providências. Disponível em: http://www.planalto.gov.br/ccivil_03/Leis/L10165.htm. Acesso em: 12 jul. 2019.

BRASIL. Lei Federal No 11.952 de 25 de junho de 2009. Dispóe sobre a regularizaçáo fundiária das ocupaçóes incidentes em terras situadas em áreas da Uniáo, no âmbito da Amazônia Legal; altera as Leis nos 8.666, de 21 de junho de 1993, e 6.015, de 31 de dezembro de 1973; e dá outras providências. Disponível em: http://www.planalto.gov. br/ccivil_03/_Ato2007-2010/2009/Lei/L11952.htm. Acesso em: 23 Set. 2019.

BRASIL. Lei Federal No 12.651 de 20 de maio de 2012. Dispóe sobre a proteçáo da vegetaçáo nativa; altera as Leis $\mathrm{No}_{s}$ 6.938, de 31 de agosto de 1981, 9.393, de 19 de dezembro de 1996, e 11.428, de 22 de dezembro de 2006; revoga as Leis Nos 4.771, de 15 de setembro de 1965, e 7.754, de 14 de abril de 1989, e a Medida Provisória No 2.166-67, de 24 de agosto de 2001; e dá outras providências. Disponível em: http:// www.planalto.gov.br/ccivil_03/_Ato2011-2014/2012/Lei/L12651.htm. Acesso em: 30 set. 2019.

BRASIL. Lei Federal No 13.123, de 20 de maio de 2015. Regulamenta o inciso II do $\$ 1^{\circ}$ e o $\$ 4^{\circ}$ do art. 225 da Constituição Federal, o Artigo 1, a alínea j do Artigo 8, a alínea c do Artigo 10, o Artigo 15 e os $\$ \$ 3^{\circ}$ e $4^{\circ}$ do Artigo 16 da Convençáo sobre Diversidade Biológica, promulgada pelo Decreto № 2.519, de 16 de março de 1998; dispóe sobre o acesso ao patrimônio genético, sobre a proteçáo e o acesso ao conhecimento tradicional associado e sobre a repartição de benefícios para conservação e uso sustentável da biodiversidade; revoga a Medida Provisória No 2.186-16, de 23 de agosto de 2001; e dá outras providências. Disponível em: http://www.planalto.gov.br/ ccivil_03/_ato2015-2018/2015/lei/l13123.htm. Acesso em: 30 Set. 2019.

BRASIL. Lei Federal No 4.504, de 30 de novembro de 1964. Dispóe sobre o Estatuto da Terra, e dá outras providências. Disponível em: http://www.planalto.gov.br/ccivil_03/ leis/14504.htm. Acesso em: 23 Set. 2019.

BRASIL. Lei Federal No 6.938 de 31 de agosto de 1981. Dispóe sobre a Política Nacional do Meio Ambiente, seus fins e mecanismos de formulação e aplicação, e dá outras 
providências. Disponível em: http://www.planalto.gov.br/ccivil_03/Leis/L6938.htm. Acesso em: 10 jul. 2019

BRASIL. Lei Federal No 9.795, de 27 de abril de 1999. Dispóe sobre a educação ambiental, institui a Política Nacional de Educação Ambiental e dá outras providências. Disponível em: http://www.planalto.gov.br/ccivil_03/leis/19795.htm. Acesso em: 01 jul. 2019.

BRASIL. Ministério da Cidadania. Relatórios de Informaçóes Sociais. Disponível em: https://aplicacoes.mds.gov.br/sagi/RIv3/geral/index.php?relatorio=153\&file=entrada\# . Acesso em: 20 set. 2019.

BRASIL. Ministério do Desenvolvimento Agrário. Politica Nacional de Assistência Técnica e Extensão Rural. Brasília, DF, 2004.

BRASIL. Ministério do Desenvolvimento Social e Combate à Fome. Guia de Políticas Sociais Quilombolas - Serviços e benefícios do Ministério do Desenvolvimento Social e Combate à Fome. Brasília, DF, 2009.

BRASIL. Ministério do Meio Ambiente. Ministério da Educação. Programa Nacional de Educação Ambiental. ProNEA. 3a edição. Brasília: Edições MMA. 2005.

BRASIL. Ministério do Meio Ambiente. Serviço Florestal Brasileiro. Programa Federal de manejo florestal comunitário e familiar. 2016. Disponível em: http://www.florestal. gov.br/florestas-comunitarias/68-fomento-florestal/602-programa-federal-de-manejoflorestal-comunitario-e-familiar. Acesso em: 02 Out. 2019.

BRASIL. Portaria No 376, de 16 de outubro de 2008. Define procedimentos para a gestão do Cadastro Único para Programas Sociais do Governo Federal, disciplinado pelo Decreto No 6.135, de 26 de junho de 2007. Disponível em: http://www.mds. gov.br/webarquivos/legislacao/bolsa_familia/_doc/portarias/2008/Portaria_GM_ MDS_376_16-10-08-1.pdf. Acesso em: 11 jun. 2019.

CALEGARE, Marcelo Gustavo Aguilar; HIGUCHI, Maria Inês Gasparetto; BRUNO, Ana Carla dos Santos. Povos e Comunidades Tradicionais: Das áreas protegidas à visibilidade política de grupos sociais portadores de identidade étnica e coletiva. Ambiente \& Sociedade, São Paulo, v. 17, n. 3, p. 115-134, 2014.

CLEMENTE, Claudelir Correa; SILVA, José Carlos Gomes da. Dos quilombos à periferia: reflexóes sobre Territorialidades e sociabilidades negras urbanas na Contemporaneidade. Critica e Sociedade: Revista de Cultura Politica. v. 4, n.1, 2014.

CONFERÊNCIA DAS NAÇÓES UNIDAS SOBRE MEIO AMBIENTE E DESENVOLVIMENTO (CNUMAD). Agenda 21. Sáo Paulo: Secretaria de Estado do Meio Ambiente, 1992.

FEISTAUER, Diogo; LOVATO Paulo Emilio; SIMINSKI, Alexandre; RESENDE, Sidivan Aparecido. Impactos do novo código florestal na regularizaçáo ambiental de propriedades rurais familiares. Ciência Florestal, Santa Maria, v. 24, n. 3, p. 749-757, 2014. 
FROEHLICH, Cristiane. Sustentabilidade: dimensóes e métodos de mensuração de resultados. DESENVOLVE: Revista de Gestáo do Unilasalle, Canoas, v. 3, n. 2, p. 151$168,2014$.

GARCIA JUNIOR, E. F; MEDEIROS, S; AUGUSTA, C. Análise documental: uma metodologia da pesquisa para a Ciência da Informaçáo. Temática, v. 13, n. 7, p. 138150, 2017.

HOFLING, Eloisa de Mattos. Estado e políticas (públicas) sociais. Cadernos Cedes, v. 21, n. 55, p.30-41, 2001.

INSTITUTO DE POLÍTICAS ECONÔMICAS APLICADAS. Politicas agroambientais e sustentabilidade: desafios, oportunidades e liçóes aprendidas. Brasília: Ipea, 2014.

LAYRARGUES, Philippe Pomier. Educação ambiental com compromisso social: o desafio da superaçáo das desigualdades. IN: LOUREIRO, Carlos Frederico Bernardo; LAYRARGUES, Philippe Pomier; CASTRO, Ronaldo de Souza (Orgs.). Repensar a Educação Ambiental: um olhar crítico. São Paulo: Cortez. p. 11-31. 2009.

MACEDO, João Heitor Silva. Cultura, educaçâa e ensino de história. Combate ao racismo: narrativas sobre a lei 10.639/03. 2018. 221f. Tese (Doutorado em História) - Centro de Ciências Sociais e Humanas, Departamento de História, Universidade Federal de Santa Maria, 2018.

MARTINS, Luciana Aparecida Ramos; NISHIJIMA, Toshio. Preservação ambiental e qualidade de vida em comunidades quilombolas. Revista Eletrônica em Gestão, Educação e Tecnologia Ambiental. REGET-CT/ UFSM. n. 1, p. 59-69, 2010.

MATTOS, Hebe. "Remanescentes das comunidades dos quilombos": Memória do cativeiro e políticas de reparação no Brasil. Revista USP, São Paulo, n. 68, p. 104-111, 2006.

MEDEIROS, Rodrigo. Singularidades do sistema de áreas protegidas para a conservaçẫo e uso da biodiversidade brasileira. In: GARAY, Irene; BECKER, Bertha (orgs.). Dimensōes Humanas da Biodiversidade. Petrópolis: Editora Vozes. p. 159-184. 2006.

MENDONÇA, Leticia Koeppel; TAVIRA, Guilherme; FERREIRA, Everton; LANGE, Roberta; OLIVEIRA, Luana Paré; MOLINA, Caroline; HORA, Karla. A construção de uma política de assistência técnica e extensão rural para superação da extrema pobreza. In: MELLO, Janine. A inclusão produtiva rural no Brasil Sem Miséria: o desafio da superação da pobreza no campo. Brasília: MDS. p. 50-69. 2015.

MINISTÉRIO PÚBLICO FEDERAL. Nota Técnica No 02/2019/ASSREV-1a CCR. 2019. Disponível em: http://www.mpf.mp.br/pgr/documentos/nota-tecnica-no-022019-reflexoes-sobre-o-decreto-9759-19-v3.pdf. Acesso em: 02 Out. 2019.

MORAIS, Henrique Michael Andreetta de Oliveira Matos de. Regularização Fundiária Rural na Amazônia Legal: Uma análise da Lei No13.465 de 11 de julho de 2017. 2017. 
58 f. Monografia (Graduação em Direito) - Faculdade de Direito, Universidade de Brasília, Brasília - Distrito Federal, 2017.

NASCIMENTO, Elimar Pinheiro do. Trajetória da Sustentabilidade: do ambiental ao social, do social ao econômico. Estudos Avançados, v. 26, n. 74, p. 51-64, 2012.

ORGANIZAÇÃO DAS NAÇÓES UNIDAS. A Agenda 2030 para o Desenvolvimento Sustentável. 2015. Disponível em: https://nacoesunidas.org/pos2015/agenda2030/. Acesso em: 01 Out. 2019.

ORGANIZAÇÃO DAS NAÇÓES UNIDAS. FAO: pastoreio causou 80\% do desflorestamento no Brasil entre 1990-2005. 2016. Disponível em: https:// nacoesunidas.org/fao-pastoreio-causou-80-do-desflorestamento-no-brasilentre-1990-2005/. Acesso em: 1 out. 2019.

RORIZ, Pedro Augusto Costa; FEARNSIDE, Philip Martin. A construção do Código Florestal Brasileiro e as diferentes perspectivas para a proteção das florestas. Novos Cadernos NAEA. v. 18, n. 2, p. 51-68, 2015.

SALES JR, Ronaldo L. Políticas de Ancestralidade: negritude e africanidade na esfera pública. CAOS - Revista Eletrônica de Ciências Sociais. N 14, p. 119 - 133, 2009.

SANTOS, Christiane Fernandes Dos; SIQUEIRA, Elisabete Stradiotto; ARAÚJO, Iriane Teresa De; MAIA, Zildenice Matias Guedes. A agroecologia como perspectiva de sustentabilidade na agricultura familiar. Ambiente \& Sociedade. Sáo Paulo, v. 17, n. 2, p. 33-52, 2014.

SÁ-SILVA, J. R; ALMEIDA, C. D; GUINDANI, J. F. Pesquisa documental: pistas teóricas e metodológicas. Revista Brasileira de História Ciências Sociais, v. 1, n. 1, p. $1-15,2009$.

SILVA, André Ricardo Fonsêca da. Políticas Públicas para comunidades quilombolas: uma luta em construçáo. Revista de Ciências Sociais, Politica e Trabalho, v. 2018, n. 48, p.115-128, 2018.

SILVESTRE, Diego de Oliveira; MOREIRA, Alecsandra P. da Costa. Uso, vivência e conservação do meio ambiente em populaçóes tradicionais: o caso da comunidade quilombola de Caiana dos Crioulos, Alagoa Grande (PB). Cadernos do Logepa, v. 6, n. 2, p. 180-202, 2011.SOARES, Ilton Araújo. Sustentabilidade socioambiental e efetividade de gestão de unidades de conservação. 2019. 219 f. Tese (Doutorado em Desenvolvimento e Meio Ambiente) - Centro de Biociências, Programa de PósGraduação em Desenvolvimento e Meio Ambiente, Universidade Federal do Rio Grande do Norte. Natal, RN, 2019.

SOGLIO, Fábio Dal; KUBO, Rumi Regina (org.). Desenvolvimento, agricultura e sustentabilidade. Porto Alegre: Editora da UFRGS, 2016. 